\title{
Lipomatous, vascular, and chondromatous benign tumors of the peripheral nerves
}

\author{
Representative cases and review of the literature
}

\author{
Claude-Edouard Châtillon, M.D., ${ }^{1}$ Marie-Christine Guiot, M.D.,2² \\ AND LINE JACQUES, M.D. ${ }^{1}$

\begin{abstract}
${ }^{1}$ Department of Neurosurgery and ${ }^{2}$ Department of Neuropathology of the Montreal Neurological Hospital, McGill University Health Center, Montreal, Quebec, Canada
\end{abstract}

\begin{abstract}
Benign peripheral nerve lesions of lipomatous, vascular, and chondromatous origin are very rare. Only one previous case of brachial plexus involvement by such a tumor has been reported. The authors report on their experience with peripheral nerve tumors in three patients and review the available literature on these topics. The three cases discussed include a 44-year-old woman with an intraneural lipoma of the right middle trunk, a 40-year-old woman with an intraneural hemangioma infiltrating the right posterior cord, and a newborn male with a predominantly cartilaginous hamartoma originating from the right $\mathrm{C}-5$ nerve root.

The literature review yielded six previous cases of intraneural lipoma, approximately 50 cases of lipofibromatous hamartoma, 13 cases of intraneural hemangioma, and no previous case of cartilaginous hamartoma originating from a nerve. Intraneural lipomas are well encapsulated, and gross-total resection can be achieved. Lipofibromatous hamartomas are diffusely infiltrative; decompressive debulking and neurolysis is often the most appropriate initial approach for patients with symptomatic lesions. Resection of intraneural hemangiomas can be achieved but may require nerve resection and repair in some cases. Debulking has been reported to provide prolonged symptomatic relief in these lesions, and preoperative embolization and postoperative radiotherapy were beneficial in the case presented here. To the authors' knowledge, this is the first reported case of a cartilaginous hamartoma infiltrating a peripheral nerve. Gross-total resection of symptomatic intraneural lipomas is feasible and apparently curative. The optimal treatment for lipofibromatous hamartomas and vascular and chondromatous lesions of the peripheral nerves is uncertain and should be guided by the severity of symptoms.
\end{abstract}

KEY WORDS - benign peripheral nerve tumor - intraneural lipoma - intraneural hemangioma - intraneural hamartoma - lipofibromatous hamartoma

$\mathrm{B}$ ENIGN PERIPHERAL NERVE TUMORS not originating from neural or Schwann cells are rare. Kline and colleagues ${ }^{17}$ documented 91 tumors either originating, infiltrating, or closely adhering to peripheral nerve elements in patients who underwent surgery at the Louisiana State University Medical Center, and classified them into 16 subtypes. In their 1999 publication, Scheithauer et al. ${ }^{38}$ described several benign and malignant tumors originating from peripheral nerves. These lesions included lipofibromatous hamartomas, neuromuscular choristomas, meningiomas, paraganglimas, intraneural lipomas, vascular tumors (including hemangiomas, angiosarcomas, and hemangioblastomas), adrenal adenomas, lymphomas, and amyloidomas. We describe two cases of rare intrinsic nonneural sheath peripheral nerve tumors and review the literature regarding lipomatous tumors and hemangiomas of peripheral nerves. We also present a case of a large intra- and paraspinal hamartoma with predomi-

Abbreviations used in this paper: GTR = gross-total resection; $\mathrm{MR}=$ magnetic resonance. nant chondromatous differentiation in close relation to the brachial plexus in an infant. To our knowledge this is the first documented case.

\section{Lipomatous Tumors}

Adipose tissue is a normal constituent of peripheral nerves, usually located within the perineurium and epineurium. Sunderland ${ }^{42}$ observed the presence of adipose cells in the interfascial tissues of nerves, more prominently in the lower extremities and in proximal (larger) nerves. Intraneural lipomatous tumors are believed to arise from these normally occurring intraneural adipose cells. The terms intraneural lipoma, median nerve lipoma, lipofibro$\mathrm{ma}$, and lipofibromatous hamartoma have been used to describe a heterogeneous group of lipomatous tumors originating from peripheral nerves. In 1978, Terzis et al. ${ }^{44}$ classified benign fatty tumors of the peripheral nerves into three types: well-encapsulated intraneural lipomas, diffusely infiltrating fibrofatty tumors (lipofibromatous hamartomas) and macrodystrophia lipomatosa (an infiltrating fibrofatty lesion with associated focal macrodactyly). In a 

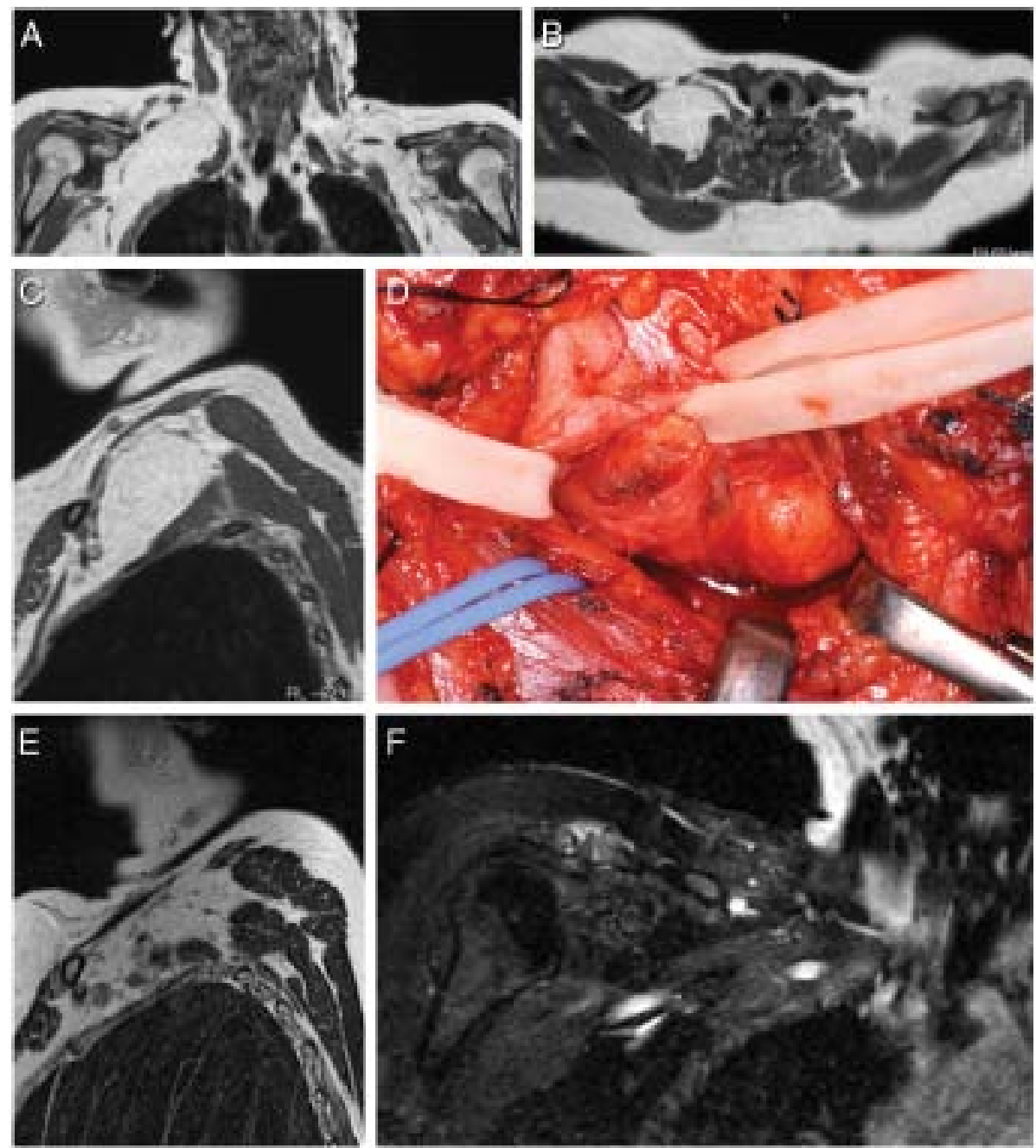

FIG. 1. Magnetic resonance images and intraoperative photographs of an intraneural lipoma. Preoperative coronal (A), axial (B), and sagittal (C) T1-weighted images demonstrating an $8.9 \times 5.2 \times 4.7-\mathrm{cm}$ supra- and infraclavicular lesion. Note the homogenous fat intensity signal. D: Intraoperative photograph of the homogeneously fatty, lobulated mass, which is significantly stretching the superior trunk (Penrose loop). Sagittal T2- (E) and coronal T1-weighted (F) fat-suppression sequences obtained at the 3-year follow-up examination. No residual or recurrent tumor was demonstrated.

review of the topic, Guthikonda et al. ${ }^{11}$ added to this scheme soft tissue lipomas causing external compression of a nerve. Because our focus is on tumors originating from nerves, the latter tumor types are not discussed here.

\section{Intraneural Lipoma}

Case 1. This 44-year-old woman was referred to our institution because of a soft right supraclavicular mass and right upper extremity dysesthesias and paresthesias radiating from the shoulder to the index and middle finger. She was otherwise healthy and had no history of trauma. On physical examination, a soft nontender mass was palpated in the deep supraclavicular tissues. No other cutaneous or soft tissue lesions were noted. The patient reported mildly decreased light touch sensation in the C-5 and C- 6 dermatomes. No motor deficits were noted. An MR image revealed an $8 \times 7 \times 5.5-\mathrm{cm}$ homogeneous fat density well-encapsulated lesion located primarily in the left su- praclavicular region, but with extension into the infraclavicular region (Fig. 1A-C). The mass displaced the subclavian blood vessels and brachial plexus structures anteriorly and inferiorly.

The patient underwent GTR of this well-encapsulated mass that was found to originate from the middle trunk (Fig. 1D). The superior trunk and suprascapular nerves appeared significantly stretched. The lesion was removed in several large fragments and was found to be of uniform lipomatous appearance. Microscopic examination revealed a uniform lesion consisting of lobules of mature adipose tissue separated by delicate fibrocollagenous septae. No atypical features were found (Fig. 2). The postoperative course was uneventful. The patient reported immediate relief of the dysesthesias after surgery. Control MR images obtained 1 and 3 years after surgery did not reveal any residual or recurrent tumor (Fig. $1 \mathrm{E}$ and $\mathrm{F}$ ).

Literature Review. Chiao and colleagues ${ }^{6}$ reviewed the literature from 1932 to 1985 and found five cases of well- 


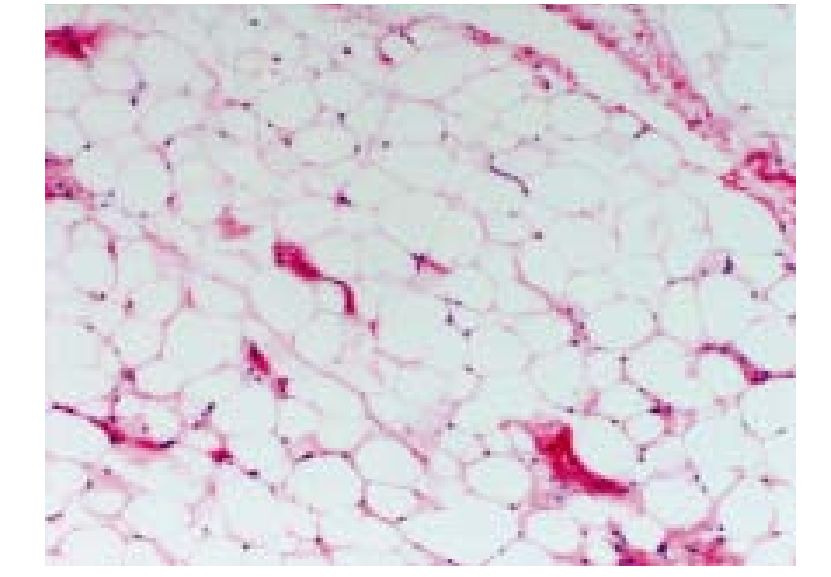

FIG. 2. Photomicrograph of the intraneural lipoma showing a omogeneous population of mature adipocytes with delicate conective tissue septations. $\mathrm{H} \& \mathrm{E}$, original magnification $\times 100$.

encapsulated lipomas arising from peripheral nerves s,12,26, $^{1}$ 37,46 to which they added their own patient. Our extensive search through Medline from 1950 to January 2007 (key word searches included "lipoma and nerve," "lipoma and peripheral nerves," "intraneural lipoma," "fibrolipoma," and "lipofibroma") did not yield any new reports of wellencapsulated intraneural lipomatous lesions.

In the reports in the literature, intraneural lipomas were usually painless or caused only minimal discomfort. The tumors arose from the median nerve, $, 126,37,46$ the sciatic nerve, ${ }^{6,12}$ or the brachial plexus (present report). All patients were women between the ages of 34 and 63 years (mean 46 years) at presentation. In five of six patients, the mass had first been noticed within 5 years of presentation; however one patient had been aware of its presence since childhood. ${ }^{46}$ Compressive neuropathic symptoms of the involved nerve were found in most cases. There was no clear origin or correlation with trauma, although a remote fall on the affected hand was noted in the medical history of one patient. ${ }^{37}$

When reported, computed tomography findings consisted of a well-encapsulated, fat density soft tissue mass with occasional septations in close proximity with the affected nerve. ${ }^{6}$ As described previously, lipomas exhibit signal characteristics consistent with those of normal adipose tissue: homogeneous hyperintensity on T1- and T2weighted sequences with suppression of the hyperintense signal on fat saturation inversion recovery sequences. The lesion's close relationship to and possible splaying of the nerve fascicles of the involved nerve may be noted, but no intracapsular nerve fascicles should be visualized. Only one previous report includes a brief description of findings on MR imaging, ${ }^{6}$ the findings in this study are consistent with those we describe in the present report.

All seven patients in the literature underwent open resection with GTR; preservation of nerve fascicle integrity was achieved in all cases. Operative observations included an obvious capsule, no significant infiltration of fascicles within the tumor, and uncomplicated enucleation of a soft lipomatous mass. No recurrences have been reported after follow-up periods varying from 3 months to 4 years. Complete or partial recovery of preoperative motor and senso-

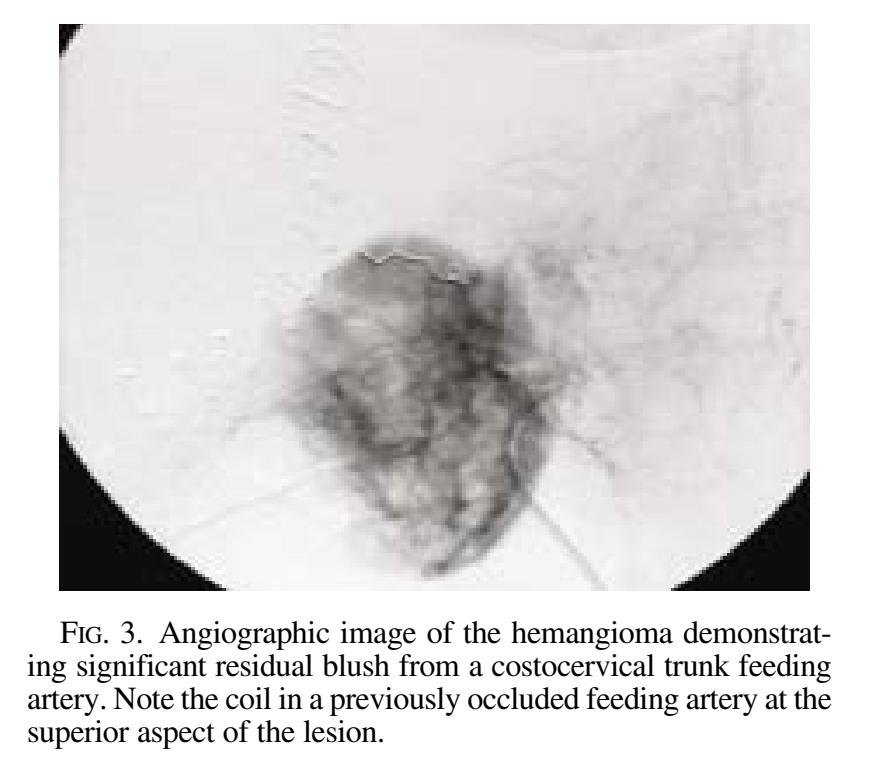

ry symptoms was reported in four patients. One patient with preoperative thenar atrophy did not recover motor function postoperatively, however. ${ }^{37}$ In another patient, a new postoperative impairment of light touch sensation on the palmar surface of the index finger persisted at the 3year follow-up examination. ${ }^{26}$ Microscopic examination of samples obtained in these cases revealed well-differentiated adipose cells within a delicate fibrous stroma. Note that intervening nerve fascicles or mitotic figures were not documented in any of the seven cases.

\section{Lipofibromatous Hamartoma}

The first description of a diffuse lipofibromatous infiltration of a nerve is commonly attributed to Mason in $1953{ }^{23}$ However, Adair et al. ${ }^{2}$ reported on two cases of lipomatous intraneural tumor with associated enlargement of surrounding bone and soft tissues as early as 1932 . Since then, almost 50 cases have been documented under different names (intraneural lipoma, lipofibroma, fibrofatty infiltration, lipomatous hamartoma). ${ }^{8,20,24,25,34,36,40,41,45}$ The designation "lipofibromatous hamartoma" was coined by Johnson and Bonfiglio, ${ }^{16}$ and is currently the most widely accepted term to describe this entity. The median and digital nerves are almost exclusively affected, although distal lesions of the ulnar, ${ }^{9}$ radial, ${ }^{14}$ superficial peroneal, ${ }^{15}$ and plantar $^{29,39}$ nerves have also been reported. Proximal lesions are very rare but have been documented in the ulnar nerve at the elbow, ${ }^{10}$ the brachial plexus,${ }^{33}$ and the sciatic nerve. ${ }^{22}$

The origin and pathogenesis of lipofibromatous hamartomas is unknown. Some authors have suggested that repetitive microtrauma may cause a reactive fibrofatty cell proliferation. ${ }^{38}$ In their review of the topic, Guthikonda et al. ${ }^{11}$ commented that lipofibromatous hamartoma

...is extremely rare compared to the occurrence of entrapment neuropathy at the carpal tunnel. The infiltrative process extends longitudinally beyond the confines of the carpal canal [...]. Although the reactive process should regress after sectioning of the carpal ligament, in most patients, the mass remains unchanged or continues to grow, despite the removal of the putative offending cause. 


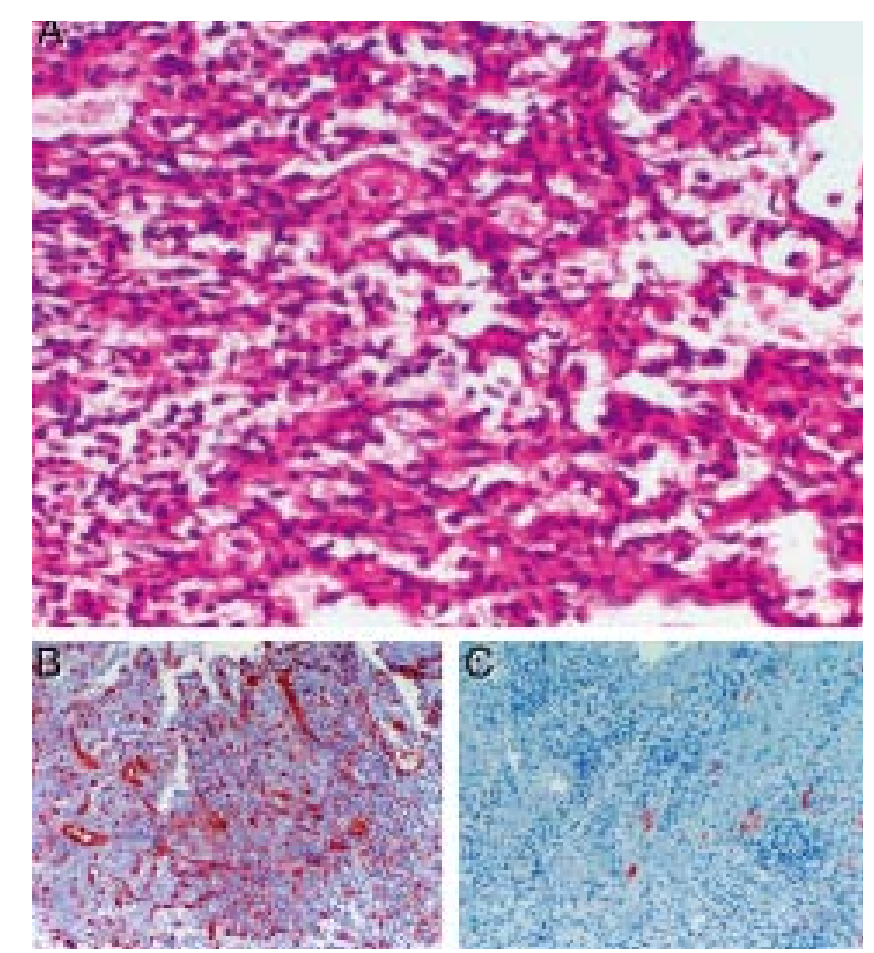

FIG. 4. Photomicrographs of intraneural hemangioma tissue sections. A: Numerous small vascular channels lined with endothelial cells are demonstrated. $\mathrm{H} \& \mathrm{E}$, original magnification $\times 100$. B: Cells stained positive for factor VIII and can be seen to line the vascular channel endothelium. C: Immunohistochemical analysis for neurofilament showing a few axons trapped within the tumoral tissue. Original magnification $\times 40$ (B and C).

No association of neurofibromatosis with this lesion has been reported. However, Amadio and colleagues ${ }^{3}$ reported on a patient with Klippel-Trelaunay-Weber syndrome and hamartomatous digital enlargement of two fingers. Because there have been no reported cases of bilateral or multiple lipofibromatous hamartoma, it seems unlikely that the lesion would represent a manifestation of a genetic disorder.

Patient age at presentation varies from infancy ${ }^{3}$ to the seventh decade,,$^{13}$ although most patients present in adolescence or early adulthood. In most patients, the mass has usually been present for several years prior to the appearance of symptoms, most commonly a compressive neuropathy of the median nerve at the carpal tunnel. Women seem to be affected twice as often as men. Digital enlargement due to fibrofatty infiltration of perineural soft tissue is common in lipofibromatous hamartomas that involve the digital nerves. In approximately one third of cases, the bone and soft tissues of the digit are diffusely enlarged, causing true macrodactyly. The lesion has then been referred to as "macrodystrophia lipomatosa." As suggested by Guthikonda et al., ${ }^{11}$ this separate designation may be superfluous, as macrodystrophia lipomatosa likely represents the extreme of a spectrum of lipofibromatous infiltration into surrounding tissues.

Pathognomonic MR imaging findings of lipofibromatous hamartoma consist of serpiginous $\mathrm{T} 1-$ and $\mathrm{T} 2-$ weighted low-intensity structures containing and surrounded by fat (hyperintense on T1- and hypointense on
T2-weighted fat suppression sequences), giving the lesion a spaghetti-like appearance on sagittal images, and a "coaxial cable-like" appearance on coronal images. ${ }^{22}$ Calcifications or enhancement after injection of Gd have not been documented.

Total resection of this lesion with preservation of neural structures has not been achieved. Several reported attempts, even with microscopy, failed to achieve safe dissection of the lesion from the invested nerve fascicles. Radical excision of the tumor with fascicular cable graft repair has been performed in the context of severe preoperative sensorimotor deficits and a debilitating tumor mass, ${ }^{11}$ yielding persistent severe deficits, albeit without a painful palmar mass. In one case of radical excision with preservation of median nerve function, a Martin-Gruber anastomosis was reported postoperatively. ${ }^{5}$ Most authors have reported either safe debulking of the mass, external neurolysis, internal neurolysis, or a combination of these approaches. Preservation and improvement of nerve function is often best achieved with external and internal neurolysis. The natural history of lipofibromatous hamartoma is slow progressive growth. Although debulking is often tedious and risks injury to the nerve fascicles, it may be necessary when the tumor mass severely impedes hand function. Gross examination reveals a fusiform dense fatty-yellow mass expanding and investing the affected nerve. Under microscopy, the lesion exhibits normal size or atrophied nerve fibers within a matrix of collagen, welldifferentiated fibroblasts, and adipocytes. Fibrofatty proliferation often extends beyond the epineurium. Mitotic figures should be absent. ${ }^{38}$

\section{Intraneural Hemangioma}

Case 2. This 40-year-old, right-hand dominant woman presented to our institution with a 1-year history of a growing, tender, right supraclavicular mass. She had no relevant medical history and had no history of neck trauma. The patient had noticed increasing right shoulder pain that radiated down to the elbow when she raised her arm. On examination, a palpable tender mass in the inferior right posterior cervical triangle was found, measuring approximately $8 \mathrm{~cm}$. Mild deltoid weakness was noted, but the results of her motor examination were otherwise normal. Paresthesias in the C-7 distribution were reproduced by raising the right arm or pressing on the mass; however, sensory examination of the arm in neutral position was unremarkable. An MR image obtained in another institution revealed a $9 \times 7-\mathrm{cm}$ ovoid rapidly enhancing mass in the right supra-and infraclavicular region, displacing subclavian blood vessels and the brachial plexus superiorly and anteriorly.

The patient underwent surgery for exploration and resection. The tumor appeared to originate in and infiltrate the inferior trunk and was adherent to adjacent nervous and vascular structures. The operation was terminated prematurely because tumor vascularity caused blood loss in excess of $800 \mathrm{ml}$. Preliminary pathological findings were consistent with a hemangioma. Angiography was performed the following day and three principal feeding arteries were identified from the costocervical trunk, the anterior cervical artery, and the transverse scapular artery, 


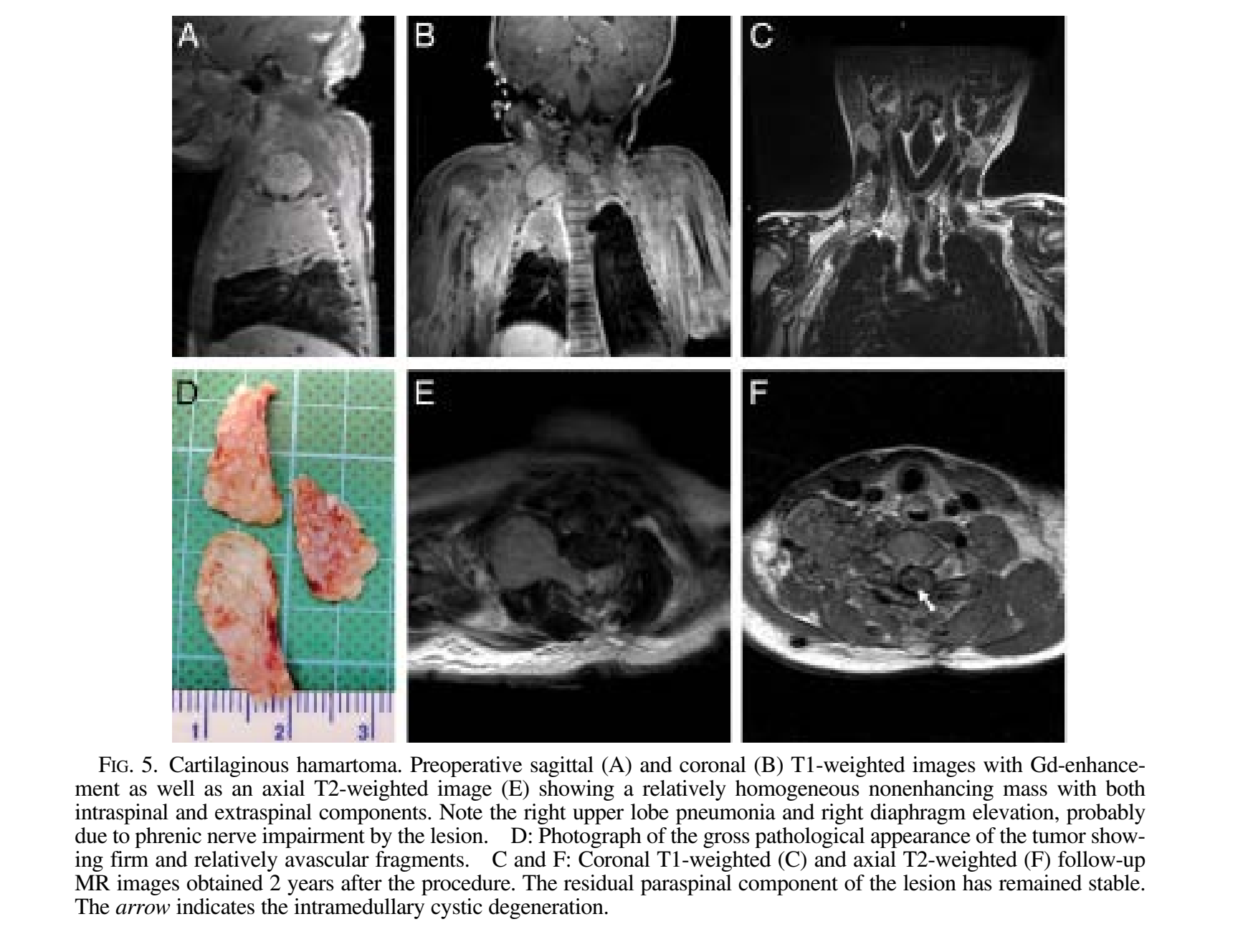

and embolized with coils and particles for almost complete obliteration of the tumoral blush (Fig. 3). Resection was attempted a second time 4 days later. Using neurostimulation, monitoring, and careful dissection so that the nerve fascicles could be preserved, approximately $50 \%$ of the lesion was removed. We did not think that the portion of tumor adherent to and likely invading the inferior trunk could be removed without injuring the intervening nerve.

Microscopic examination revealed a fibrous lesion composed of loose vascular-type tissue with uniform cells and numerous vascular channels. The vascular channel lining stained strongly positive for immunohistochemical endothelial markers factor VIII and CD31. A few intermingled axons were noted in some areas (Fig. 4).

Postoperatively we noted weakness in the deltoid (Grade $2 / 5$ ), biceps (3/5), and extensors (triceps, wrist, and hand extensors $3 / 5$ ), and increased numbness in the patient's fourth and fifth digits. The patient was referred to the radiooncology service for adjuvant radiotherapy, and underwent 22 treatments of $2-\mathrm{Gy}$ radiation to the tumor bed for a total 44 Gy over 30 days. After radiotherapy had been completed, she was followed up at another institution. Follow-up MR images obtained 2 years later revealed that the mass had decreased in size $(3.6-\mathrm{cm}$ greatest diameter) compared with its size on the immediate postoperative MR image. The patient was asymptomatic and the results of the motor and sensory examinations were unremarkable.

Literature Review. Benign vascular tumors originating from peripheral nerves are rare. A review of the literature revealed 13 previously reported cases, $7,18,19,21,30-32,47$ to which we add our own. The first account of this lesion type is attributed to Purcell and Gurdjian in $1935 .{ }^{35}$ Most patients present in childhood ${ }^{38}$ with a painful, soft mass along the path of a nerve. The median nerve is most commonly affected (six cases), followed by the tibial (three cases), ulnar, digital, sciatic, and superficial peroneal nerves. In all but two of the reported cases, the patients were women. Magnetic resonance characteristics reported in the literature include hyperintense signal on T1- and T2weighted images with fat suppression sequences. Flow voids are usually apparent and feeding vessels may be visualized; these lesions are also noted to enhance after Gd-addition. On angiography an early and persistent tumoral blush is demonstrated. When possible, GTR was apparently curative, with follow-up periods ranging from 6 weeks to 4 years (in five cases). ${ }^{7,18,19,31,47}$ In three of these cases, $7,18,47$ resection with nerve preservation was achieved. In the other two, ${ }^{19,31}$ en bloc resection with the involved nerves was performed, followed by cable fascicular graft repair. Patel and colleagues ${ }^{31}$ reported partial 


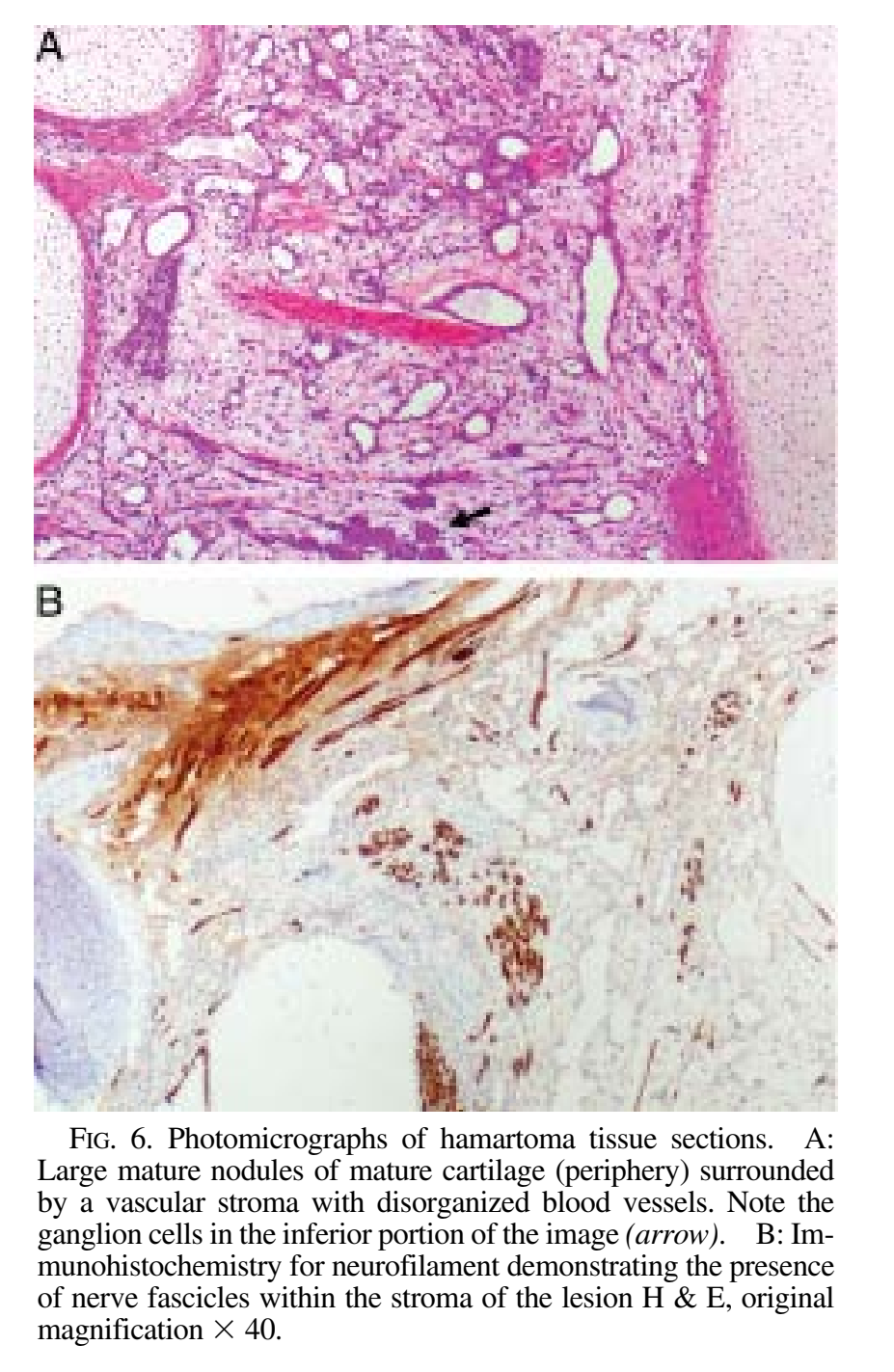

recovery of median nerve motor and sensory function after en bloc resection at the 4-year follow-up examination (pinch grip $7.5 \mathrm{~kg}$ and hypesthesia in the index finger with prolonged distal latencies). Kon and Vuursteen ${ }^{19}$ described complete postoperative recovery in the sensory distribution of the resected digital nerve.

Partial resection usually provides pain relief and alleviation of neuropathic symptoms for variable periods of time. In two reported cases, ${ }^{31}$ incomplete resection resulted in the recurrence of symptoms within 3 years. One patient was treated conservatively with a compressive glove for another 3 years, but at the time of publication of the article by Patel and colleagues, the symptoms had again recurred despite this measure. The second patient underwent en bloc resection with graft repair at the time of recurrence, as described above.

Although the use of radiotherapy has yielded some favorable results in treating hemangiomas at other anatomical sites, ${ }^{28,43}$ its use in the treatment of intraneural hemangiomas was not previously reported. The decrease in tumor size seen on serial follow-up images in the current case may have been radiation-induced, although the contribution of embolization to this shrinkage cannot be determined.
On macroscopic examination, a soft hemorrhagic mass may be seen splaying apart and infiltrating the nerve fascicles. A vascular pedicle may also be demonstrated. Microscopically, most peripheral nerve hemangiomas are cavernous, consisting of large endothelium-lined vascular channels with minimal intervening connective tissue and sparse myocytes. Capillary hemangiomas have also been reported, ${ }^{38}$ showing typical lobular architecture with multiple small vascular channels within a cellular matrix, as well as intervening nerve fascicles (Fig. 4). The cells lining the vascular channels are positive for factor VIII and CD31 endothelial immunohistochemical markers.

\section{Cartilaginous Hamartomas}

Case 3. This 9-day-old male infant, born at full term via cesarean section due to shoulder dystocia and heart decelerations, was transferred to our institution for assessment of a paraspinal mass. The patient's body had been hypotonic from birth, most prominently in the upper extremities. Other congenital abnormalities included right-sided diaphragm paralysis requiring plication, a large port-wine stain over the right shoulder and trunk, and mild upper extremity asymmetry, with the right arm 1-cm longer than the left, without any obvious soft tissue or osseus hypertrophy.

Brain and spinal MR images obtained at another institution demonstrated a dumbbell-shaped intra- and extraspinal homogeneous nonenhancing lesion at the cervicothoracic junction, which extended into the subclavian space to the superoanterior chest wall (Fig. 5A, B, D). Biopsy sampling attempted through the thoracotomy (created for diaphragmatic plication) was nondiagnostic. The neonate was then transferred to our institution for evaluation and treatment. On examination, he had bilateral flaccid upper extremities with paralysis and absent reflexes. His lower extremities were markedly hypotonic with minimal movement to stimulation, and monoreflexic.

The child underwent GTR of the intraspinal extradural and intradural components of the tumor via a C2-T4 laminotomy and performed in two stages. The tumor was found to enter the right C-5 foramen and was inextricably encasing the nerve root at that level. Definite planes with the cord, other nerve roots, dura mater, and bone were otherwise developed. The right C-5 root was therefore sacrificed. A third stage was undertaken to debulk the right paraspinal extension of the mass. The lesion was stretching and displacing the brachial plexus but was easily dissected from the divisions and trunks. The extraforaminal C-5 root was once again intimately involved with the tumor at the right C-5 foramen, and was resected with the tumor.

Microscopic examination of the various fragments demonstrated similar histological features consisting of an overwhelming predominance of mature cartilaginous tissue with the presence, in some areas, of well-differentiated ganglion cells, disorganized blood vessels and axons (Fig. 6). They were reported as hamartomatous.

The patient's postoperative course was complicated by respiratory infections. Minimal progressive improvement in lower and upper extremity function was noted prior to discharge. The pediatric genetics service was involved to 
evaluate the patient regarding the coexistence of the hamartoma, the cutaneous lesion, and the limb assymetry, but no syndrome was identified. At a follow-up examination when he was 2 years of age, the patient was found to be quite functional, despite a notable weakness in the right arm (deltoid 4/5, biceps 4-/5, interossei 4-/5). His lower extremities were strong, and he was starting to support his own weight independently; the child's cognitive development was normal.

Literature Review. A review of the literature did not yield any previous reports of predominantly cartilaginous hamartomas related to the brachial plexus or paraspinal tissues. In their report on 10 patients, Morris et al. ${ }^{27}$ described the spinal hamartomas as midline dorsal masses with or without intraspinal extension. Five of these patients had cutaneous stigmata: four had cutaneous hemangiomas, and one had a midline dorsal dimple. All lesions were in the thoracic, lumbar, or sacral areas. Only one patient reported neurological symptoms, which consisted of L5-S1 weakness. Prominent cartilaginous differentiation was not described as a striking feature in these cases.

Approximately 80 cases of chondromatous hamartoma have been previously reported. These typically solitary chest wall lesions are composed of nodules of proliferating hyaline cartilage admixed with intervening connective tissue septae. ${ }^{4}$ Ossification and disorganized blood vessels were found in some cases. Cases of multiple hamartomas and similar pulmonary lesions have also been reported. ${ }^{4}$ However, to our knowledge, spinal or brachial plexus involvement has not been previously documented. Furthermore, the intradural and extradural location of the tumor and its intimate relationship with the right C-5 nerve root suggest that the tumor originated from the root or its sleeve at the level of the foramen. The potential diagnosis of teratoma would have required the presence of tissues from all three germ-cell layers, including elements heterologous to the site of the lesion. In this case, the mass did not contain structures of endodermal origin, and the neuroectodermal and mesenchymal structures found within the tumor were homologous to the site.

\section{Conclusions}

Benign peripheral nerve tumors of lipomatous and vascular origin are very rare. Although we currently have only limited knowledge of their origin and optimal management because of the paucity of reported cases with prolonged follow-up, a few suggestions may be extrapolated from the available literature. 1) Intraneural lipomas and hemangiomas usually appear in patients at a younger age compared to lipofibromatous hamartomas, which are typically brought to medical attention in adulthood. 2) The distinct MR imaging characteristics allow differentiation between the three types of lesions based on the preponderance of fat (lipomatous compared with vascular tumors) and the presence of intervening nerve fascicles (lipomas compared with lipofibromatous hamartomas). 3) Intraneural lipomas are well-encapsulated, and can usually be resected completely while preserving the involved nerve. Gross-total resection appears to be curative. 4) Lipofibromatous hamartomas infiltrate the nerve diffusely and grow slowly. External and internal neurolysis usu- ally provide relief of symptoms in patients with these lesions. En bloc resection with neural graft repair may be contemplated in the context of a large tumor causing severe neurological deficits and mechanical impairment of function. 5) Gross-total resection of hemangiomas may be curative. Resection with preservation of neural structures has succeeded in few cases. En bloc resection with neural graft repair has yielded acceptable results, possibly because of the plasticity and nerve regeneration potential of these young patients, or the presence of Martin-Gruber anastomoses. Partial resection usually results in symptom recurrence within a few years. Postoperative radiotherapy appears to have contributed to tumor regression in the case presented here. Future studies should be published by plastic surgeons and neurosurgeons with extensive experience in peripheral nerve surgery to expand our epidemiological, pathological, and prognostic knowledge of these entities.

\section{References}

1. Abu Jamra FN, Rebeiz JJ: Lipofibroma of the median nerve. J Hand Surg [Am] 4:160-163, 1979

2. Adair FE, Pack GT, Farrior JH: Lipomas. Am J Cancer 16: 1104-1120, 1932

3. Amadio PC, Reiman HM, Dobyns JH: Lipofibromatous hamartoma of nerve. J Hand Surg [Am] 13:67-75, 1988

4. Amstalden EM, Carvalho RB, Pacheco EM, Oliveira-Filho A, Stragea-Neto L, Rosenberg AE: Chondromatous hamartoma of the chest wall: description of 3 new cases and literature review. Intl J Surg Pathol 14:119-126, 2006

5. Bergman FO, Blom SEG, Stenstrom SJ: Radical excision of fibro-fatty proliferation of the median nerve with no neurological loss of symptoms. Plast Reconstr Surg 46:375-380, 1970

6. Chiao HC, Marks KE, Bauer TW, Pflanze W: Intraneural lipoma of the sciatic nerve. Clin Orthop Relat Res 221:267-271, 1987

7. Coessens B, De Mey A, Lacotte B, Vandenbroeck D: Carpal tunnel due to an haemangioma of the median nerve in a 12year-old child. Ann Chir Main Memb Super 10:255-257, 1991

8. Friedlander HL, Rosenberg NJ, Graubard DJ: Intraneural lipoma of the median nerve. Report of two cases and review of the literature. J Bone Joint Surg Am 51:352-362, 1969

9. Frykman GK, Wood VE: Peripheral nerve hamartoma with macrodactyly in the hand: report of three cases and review of the literature. J Hand Surg [Am] 34: 307-312, 1978

10. Gouldesbrough DR, Kinny SJ: Lipofibromatous hamartoma of the ulnar nerve at the elbow: brief report. J Bone Joint Surg Br 71:331-332, 1989

11. Guthikonda M, Rengachary SS, Balko MG, van Loveren H: Lipofibromatous hamartoma of the median nerve: case report with magnetic resonance imaging correlation. Neurosurgery 35:127-131, 1994

12. Godquin B, Brunelli M, Basso M: [Giant lipoma of the sciatic nerve.] Chirurgie 104:221-224, 1978 (Fr)

13. Hauck RM, Banducci DR: The natural history of a lipofibromatous hamartoma of the palm: a case report. J Hand Surg [Am] 18:1029-1031, 1993

14. Herrick RT, Godsil RD Jr, Widener JH: Lipofibromatous hamartoma of the radial nerve: a case report. J Hand Surg [Am] 5:211-213, 1980

15. Hirakawa E, Miki H, Kobayashi S, Ohmori M, Arima N: Lipofibromatous hamartoma of nerve in the foot. Acta Pathol Jpn 43:265-267, 1993

16. Johnson RJ, Bonfiglio M: Lipomatous hamartoma of the median nerve. J Bone Joint Surg Am 51:984-990, 1969 
17. Kline DG, Hudson AR, Tiel R, Guha AB: Management of peripheral nerve tumors, in Winn HR: Youmans Neurological Surgery, ed 5. Philadelphia: Elsevier, 2004, pp 3941-3957

18. Kojima T, Ide Y, Marumo E, Ishikawa E, Yamashita H: Haemangioma of median nerve causing carpal tunnel syndrome. Hand 8:62-65, 1976

19. Kon M, Vuursteen PJ: An intraneural hemangioma of a digital nerve-case report. J Hand Surg [Am] 6: 357-358, 1981

20. Kronberger P, Rainer C, Hittmair A, Anderl H: Lipofibromatous hamartoma (neural lipofibroma) of a flexor nerve of the index finger. Scand J Plast Reconstr Hand Surg 32:237-239, 1998

21. Losli J: Intrinsic hemangioma of the peripheral nerves, a report of two cases and a review of the literature. AMA Arch Pathol 53:226-232, 1952

22. Marom EM, Helms CA: Fibrolipomatous hamartoma: pathognomonic on MR imaging. Skeletal Radiol 28:260-264, 1999

23. Mason ML: Presentation of cases. Proceedings of the American Society of Surgery of the Hand. J Bone Joint Surg 35A: 273-275, 1953

24. Meyer BU, Roricht S: Fibrolipomatous hamartoma of the proximal ulnar nerve associated with macrodactyly and macrodystrophia lipomatosa as an unusual cause of cubital tunnel syndrome. J Neurol Neurosurg Psychiatry 63:808-810, 1997

25. Mikhail IK: Median nerve lipoma in the hand. J Bone Joint Surg Br 46:726-730, 1964

26. Morley GH: Intraneural lipoma of the median nerve in the carpal tunnel. Report of a case. J Bone Joint Surg Br 46: 734-735, 1964

27. Morris GF, Murphy K, Rorke LB, James HE: Spinal hamartomas: a distinct clinical entity. J Neurosurg 88:954-961, 1998

28. Ogino I, Torikai K, Kobayashi S, Aida N, Hata M, Kigasawa H: Radiation therapy for life-or function-threatening infant hemangioma. Radiology 218:834-839, 2001

29. Ogose A, Hotta T, Higuchi T, Katsumi N, Koda H, Umazu H: Fibrolipomatous hamartoma in the foot: magnetic resonance imaging and surgical treatment: a report of two cases. J Bone Joint Surg Am 84:432-436, 2002

30. Ouarab M, Harfaoui A, Hassoun J, Trafeh M: [Ulnar nerve hemangioma associated with hemangioma of the epitrochlean muscles. A case report.] Ann Chir Main Memb Super 16: 339-341, 1997 (Fr)

31. Patel CB, Tsai TM, Kleinert HE: Hemangioma of the median nerve: a report of two cases. J Hand Surg [Am] 11:76-79, 1986

32. Peled I, Iosipovich Z, Rousso M, Wexler M: Hemangioma of the median nerve. J Hand Surg [Am] 5:363-365, 1980

33. Price AJ, Compson JP, Calonje E: Fibrolipomatous hamartoma of nerve arising in the brachial plexus. J Hand Surg [Br] 20: 16-18, 1995
C. E. Châtillon, M. C. Guiot, and L. Jacques

34. Pulvertaft RG: Unusual tumors of the median nerve. J Bone Joint Surg Br 46:731-733, 1964

35. Purcell FH, Gurdjian ES: Hemangiomata of peripheral nerves with report of a case of cavernous hemangioma of the sciatic nerve. Am J Surg 30:541-544, 1935

36. Razzaghi A, Anastakis DJ: Lipofibromatous hamartoma: review of early diagnosis and treatment. Can J Surg 48: 394-399, 2005

37. Rusko RA, Larsen RD: Intraneural lipoma of the median nerve-case report and literature review. J Hand Surg [Am] 6:388-391, 1981

38. Scheithauer BW, Woodruff JM, Erlandson RA: Tumors of the Peripheral Nervous System. Atlas of Tumor Pathology, 3rd Series, Fascicle 24. Washington, DC: Armed Forces Institute of Pathology, 1997

39. Silverman TA, Enzinger FM: Fibrolipomatous hamartoma of the nerve. A clinicopathologic analysis of 26 cases. Am J Surg Pathol 9:7-14, 1985

40. Steentoft J, Sollerman C: Lipofibromatous hamartoma of a digital nerve. A case report. Acta Orthop Scand 61:181-182, 1990

41. Strickland JW, Steichen JB: Nerve tumors of the hand and forearm. J Hand Surg [Am] 2:285-291, 1977

42. Sunderland $\mathrm{S}$ : The adipose tissue of peripheral nerves. Brain 68:118-122, 1945

43. Suparna HC, Vadhiraja BM, Apsani RC, Seetharamaiah T, Fernandes DJ, Rao K, et al: Symptomatic vertebral hemangiomas - results of treatment with radiotherapy. Ind J Radiol Imag 16:37-40, 2006

44. Terzis JK, Daniel RK, Williams HB, Spencer PS: Benign fatty tumors of the peripheral nerves. Ann Plastic Surg 2:193-216, 1978

45. Warhold LG, Urban MA, Bora FW Jr, Brooks JS, Peters SB: Lipofibromatous hamartoma of the median nerve. J Hand Surg [Am] 8:1032-1037, 1993

46. Watson-Jones R: Encapsulated lipoma of the median nerve at the wrist. J Bone Joint Surg Br 46:736, 1964

47. Wood MB: Intraneural hemangioma: report of a case. Plast Reconstr Surg 65:74-76, 1980

Manuscript submitted March 15, 2007.

Accepted April 24, 2007.

Address reprint requests to: Line Jacques, M.D., Hôpital Neurologique de Montréal, 3801 rue Université, Montréal, Québec, Canada H3A 2B4. email: ljacques2@yahoo.ca. 